\title{
Clinical use of gatifloxacin ophthalmic solution for treatment of bacterial conjunctivitis
}

This article was published in the following Dove Press journal:

Clinical Ophthalmology

16 April 201 I

Number of times this article has been viewed

\author{
Lorenzo J Cervantes \\ Francis S Mah \\ Department of Ophthalmology, \\ Cornea and External Disease, \\ University of Pittsburgh Medical \\ Center, Pittsburgh, Pennsylvania, USA
}

Correspondence: Francis S Mah Charles T Campbell Ophthalmic Microbiology Laboratory, Eye and Ear Institute, 6th Floor, 203 Lothrop Street, Pittsburgh, PA I52/3, USA

$\mathrm{Tel}+\mathrm{I} 4126472214$

Fax + I 4I26475II9

Email mahfs@upmc.edu

\begin{abstract}
Bacterial conjunctivitis is a common infectious disease of the eye, characterized by conjunctival hyperemia, eyelid edema, and purulent discharge. Although the prevalence and incidence are not well reported, bacterial conjunctivitis represents one of the most frequent causes of patient visits to both primary care physicians and ophthalmologists. Most cases of nongonococcal and nonchlamydial bacterial conjunctivitis are self-limiting and may resolve without intervention. There is a place for treatment, however, which allows for a shorter time to clinical and microbiological resolution which may decrease the mild morbidity, decrease health care costs of visits and potential complications, return patients back to school or the work force, and limit the potential spread of this communicable infection. Gatifloxacin ophthalmic solution is a broad spectrum 8-methoxyfluroroquinolone bactericidal antibiotic, with good activity against Staphylococcus aureus, Streptococcus species, and Gram-negative pathogens. It also has a relatively good resistance profile, making it a more than adequate choice in the treatment of bacterial conjunctivitis when therapy is warranted.
\end{abstract}

Keywords: gatifloxacin, Zymar ${ }^{\circledR}, Z$ ymaxid ${ }^{\circledR}$, bacterial conjunctivitis

\section{Introduction}

Conjunctivitis, or inflammation of the conjunctiva, refers to a diverse group of diseases or disorders that primarily affect the conjunctiva. It can be broadly classified as infectious or noninfectious, with infectious etiologies of conjunctivitis caused by viruses, fungi, parasites, and bacteria. Conjunctivitis can also be further classified as acute, chronic, or recurrent. A hyperacute form of mucopurulent conjunctivitis also exists which is specifically caused by infection from Neisseria gonorrhea.

\section{Epidemiology}

Collectively, conjunctivitis represents one of the most frequent causes of patient visits to ophthalmologists and other health care personnel, including optometrists, emergency physicians, pediatricians, family physicians, and internists. ${ }^{1}$ The incidence of bacterial conjunctivitis is difficult to determine because most cases of infectious bacterial conjunctivitis are self-limiting, and many cases are treated empirically without cultures by physicians in specialties outside of ophthalmology. ${ }^{2}$

Most cases of bacterial conjunctivitis are caused by Gram-positive commensal organisms that are part of the normal skin flora. In 1975, Perkins et al reported results of isolates from 267 eyes with conjunctivitis. Staphylococcus epidermidis was the aerobic organism most often observed (67.8\%), followed by Staphylococcus aureus (23.1\%). Propionibacterium acnes was the most commonly isolated anaerobic bacteria 
(46.2\%) followed by Peptostreptococcus species $(29.3 \%){ }^{3}$ Similarly, Brook et al reported a series of positive cultures from 120 patients with acute conjunctivitis presenting over a three-month period at the end of 1975. S. epidermidis (49.6\%) was the organism most frequently isolated from eyes with inflamed conjunctiva, followed by Propionibacterium (22.9\%), Diphtheroids (18.3\%), and S. aureus (17.5\%). ${ }^{4}$ In 1995, Everett et al reported 385 bacterial isolates from patients with bacterial conjunctivitis over a one-year period. Gram-positive organisms accounted for $75 \%$ of the isolates, with coagulase-negative staphylococci and $S$. aureus being the two most commonly found (39\% and $21 \%$, respectively). ${ }^{5}$ More recently, Cavuoto et al reported results from 1254 culture-positive isolates identified from 2408 consecutive conjunctival cultures evaluated for acute bacterial conjunctivitis between 1994 and 2003. S. aureus was the most frequent isolate $(37.6 \%){ }^{6}$

In addition to skin flora, Gram-negative organisms, specifically Haemophilus influenzae, may be a significant etiology of bacterial conjunctivitis, especially in children. Brook compared organisms recovered from 119 children with conjunctivitis with 60 controls. The organisms found more frequently in inflamed eyes as compared with normal eyes were $S$. aureus $(P<0.05)$, Streptococcus pneumoniae $(P<0.002)$, and $H$. influenzae $(P<0.001) .{ }^{4}$ Gigliotti et al found a similar result when they compared conjunctival cultures of 99 patients with conjunctivitis with 102 ageand season-matched controls. The two organisms most statistically associated with bacterial conjunctivitis were H. influenzae (42\% versus $0 \%)$ and S. pneumoniae $(12 \%$ versus $3 \%){ }^{7}$

Length of stay in neonatal intensive care units has been shown to affect isolates of nongonococcal and nonchlamydial causes of bacterial conjunctivitis in neonates. Longer admission stays were associated with higher rates of Gram-positive pathogens, especially methicillin-susceptible S. aureus (MSSA) and Enterococcus species. Pseudomonas aeruginosa and Serratia marcescens were frequent isolates after the first 10 days of admission, presumably from iatrogenic transmission. Conversely, longer stays were associated with decreasing frequency of Klebsiella pneumoniae and Escherichia coli, which presumably were acquired early from vertical transmission. ${ }^{8}$

In the largest series of conjunctival cultures ever published, Abedayo et al reported the results of 12,134 positive cultures from 20,180 cultures for presumed bacterial conjunctivitis over an 11.5-year period. $S$. aureus was the most commonly identified isolate (38.7\%). Of these, methicillin-resistant
S. aureus (MRSA) comprised about 30\%. The next most common organisms were $S$. viridans $(8.1 \%), S$. pneumoniae (7.6\%), H. influenzae (6.9\%), P. aeruginosa (4.8\%), and S. marcescens $(2.4 \%)$. Positive biennial increases were noted for $S$. aureus (+2.78\%), S. pneumoniae (+0.87\%), S. viridans $(+1.55 \%)$, and $P$. aeruginosa $(+1.94 \%){ }^{9}$

\section{Clinical presentation}

Predisposing factors for developing bacterial conjunctivitis include contact with an infected individual, oculogenital spread, infection or abnormality of adnexal structures, lid malposition, severe tear deficiency, immunosuppression, and trauma. Infants and children may have nasolacrimal duct obstruction, concomitant bacterial otitis media or pharyngitis, or nasopharyngeal bacterial colonization as well. Neonates might acquire organisms from an infected mother or from inadequate prenatal care. ${ }^{10}$ Clinical signs include purulent discharge, eyelid edema, conjunctival hyperemia, conjunctival membranes or pseudomembranes, papillary hypertrophy, and follicular hyperplasia. ${ }^{2}$

Positive bacterial cultures in children with acute conjunctivitis have been associated with a history of sticky eyelids/ eyelashes in the morning, mucoid or purulent eye discharge, and examination findings of crusting or gluing of the eyelids/ eyelashes, lack of sensation of burning eyes, and the absence of watery discharge. ${ }^{11}$ In a prospective study of 428 children aged 2-36 months diagnosed with acute conjunctivitis in Israel, clinical signs were associated with pathogen cultures. Recurrent conjunctivitis was more common in patients with cultures yielding more than one pathogen. H. influenzae was associated with fever and concomitant acute otitis media. $H$. influenzae was also more associated with bilateral bacterial conjunctivitis compared with $S$. pneumoniae or mixed infection. $^{12}$

\section{Natural history}

Cases of bacterial conjunctivitis in developed countries tend to be self-limiting in adults and rarely lead to serious long-term complications. Two exceptions to this are Staphylococcus ${ }^{13}$ and Moraxella. ${ }^{14}$ In either case, the organisms colonize the skin of the eyelid, which may be a risk factor for chronicity. ${ }^{2}$ Untreated cases may continue to persist, and possibly cause severe damage, such as corneal infection. ${ }^{15,16}$

\section{Why we treat conjunctivitis}

Although most cases of bacterial conjunctivitis might improve without treatment, instilling antibiotic therapy can reduce the duration of signs and symptoms by a significant 
amount. A meta-analysis by Sheik and Hurwitz consisting of 1034 patients in five double-blind, placebo-controlled trials suggested that topical antibiotics are of benefit in improving early (days 2-5) and late (days-10) clinical and microbiological remission in patients with bacterial conjunctivitis. They state that acute bacterial conjunctivitis is frequently a selflimiting condition, because clinical cure/significant improvement occurred by days $2-5$ in $65 \%$ (95\% confidence interval [CI] 59\%-70\%) of those treated with placebo. Meta-analysis of early (days 2-5) and late (days 6-10) clinical and microbiological outcomes revealed that topical antibiotics are of benefit in improving early clinical (risk ratio [RR] 1.24; 95\% CI 1.05-1.45) and microbiological (RR 1.77; 95\% CI 1.23-2.54) remission. These benefits were reduced, but nonetheless persisted, for late clinical (RR 1.11; 95\% CI 1.02-1.21) and microbiological (RR 1.56; 95\% CI 1.17-2.09) remission. Results from this meta-analysis show that the number needed to treat for early clinical remission was six, and for late clinical remission was $13 .{ }^{17}$ Given the relatively high incidence of bacterial conjunctivitis, a shortened clinical course may have socioeconomic benefits, such as limiting the number of days children are unable to return to school until they are either treated or cured. There may also be a trickle-down effect because parents who may have had to take days off work to watch children who had to stay home from school, or babysitters/nannies who needed to be hired for the days off school also impact the family social unit negatively. ${ }^{18}$

\section{Treatment of conjunctivitis}

Antibiotic therapy consists of a broad-spectrum agent when the organism is not known or targeted therapy after identification and susceptibilities of the pathogen have been achieved. Conjunctivitis due to Chlamydia and gonococcal species, and complicated $H$. influenzae conjunctivitis in children associated with acute otitis media, requires systemic therapy. Many randomized, controlled studies of topical antibiotic treatments for conjunctivitis have been published, and almost all of the trials showed little difference in efficacy between the comparative agents. ${ }^{19,20}$ An exception is one study published in 1983 that showed chloramphenicol to be inferior to combinations of neomycin-polymyxin B-gramicidin and trimethoprim-polymyxin B. ${ }^{21}$

Treatment of acute infectious conjunctivitis in adults is often started empirically at the time of presentation, and often without pursuit of etiology. Results from a survey of general practitioners in the UK showed that $95 \%$ usually prescribe topical antibiotics for acute infectious conjunctivitis.
Of those surveyed, $67 \%$ have never pursued culture of the infection. It also reported that $46 \%$ used a delayed prescription strategy (providing a prescription to use if required after a few days). ${ }^{22}$ Delaying antibiotic treatment has been shown to reduce antibiotic use and reduce patient revisits for eye infections, with similar duration and severity of symptoms when compared with immediate prescribing. ${ }^{23}$ These findings reflect a common practice of prescribing antibiotics when it may not be completely necessary, which might contribute to the selection of resistant organisms.

\section{Emerging resistance in microbiology and conjunctivitis}

In 2003, Kowalski et al reported trends of emerging resistance of bacterial pathogens isolated from endophthalmitis, keratitis, conjunctivitis, and blepharitis to commonly used antibiotics over a nine-year period. Coagulase-negative staphylococci isolated from patients with blepharitis showed an increased trend of erythromycin resistance, with a susceptibility of $61 \%$ in 1993 compared with $20 \%$ in 2001; susceptibility to second-generation fluoroquinolones for conjunctivitis and blepharitis isolates was $100 \%$ in 1993 , $25 \%$ in 1999 , and $70 \%$ in 2001 . Similar trends for secondgeneration fluoroquinolones were seen in $S$. aureus isolates. For all pathologies, the susceptibility was over $90 \%$ in 1993 , but decreased to $70 \%$ for conjunctivitis and blepharitis, to $50 \%$ for keratitis, and to $0 \%$ for endophthalmitis in $2001 .{ }^{24}$

The Ocular Tracking Resistance in the US Today (TRUST) program purports to monitor in vitro susceptibility of pathogens isolated from ocular infections. Its first annual survey, Ocular TRUST I, reported the results of prospectively surveyed in vitro susceptibility testing (the data however, was retrospectively reported from those centers who answered the survey) from October 2005 through June 2006 for isolates of $S$. aureus, $S$. pneumoniae, and $H$. influenzae. They showed that although fluoroquinolones were active against MSSA, most MRSA isolates exhibited highlevel resistance to the class and other drugs tested. Among the $S$. pneumoniae isolates, all showed high susceptibility to the fluoroquinolones, with $100 \%$ in vitro susceptibility to levofloxacin, gatifloxacin, and moxifloxacin. Although 44\% of the $H$. influenzae isolates were beta-lactamase-positive, all isolates were susceptible to the antibiotics tested..$^{25}$

A retrospective cross-sectional study examining organism and antibiotic susceptibility trends in patients with bacterial conjunctivitis from 1994 to 2003 showed a threefold increase in resistance of Gram-positive organisms to ciprofloxacin $(11.7 \%$ to $35.6 \%, P<0.001)$ and oxacillin 
(11.6\% to $36.7 \%, P=0.001)$. S. aureus isolates demonstrated over a four-fold increase in resistance ( $8.7 \%$ to $36.7 \%)$ during the same time period. ${ }^{6}$

The report by Adebayo et al evaluated trends in antibiotic resistance of bacterial conjunctivitis isolates over an 11.5-year period. There was an overall two-fold increase in resistance ( $24 \%$ to $45 \%$ ) to erythromycin by Gram-positive isolates, with the most significant increases in $S$. aureus and alpha-hemolytic Streptococci $(P<0.0001)$. They observed a six-fold increase in resistance of the Gram-positive isolates group to ciprofloxacin ( $5 \%$ to $30 \%, P=0.002)$, as well as the Gram-negative isolates group ( $1 \%$ to $16 \%, P=0.0131)$. All isolates demonstrated low resistance to gatifloxacin and moxifloxacin $(0 \%$ to $6 \%)$ until the last year, during which a 4-5-fold increase in resistance of the Gram-positive isolates were observed. Oxacillin exhibited an increase in resistance of $2 \%$ to $40 \%(P<0.0001)$ for $S$. aureus, reflecting a significant increase in prevalence of MRSA. ${ }^{9}$

\section{Classification of fluoroquinolones}

Fluoroquinolones are synthetic fluorinated analogs of nalidixic acid. Nalidixic acid, the first antibacterial quinolone, was introduced in 1963 during chloroquine synthesis. Quinolones block bacterial DNA synthesis by inhibiting the topoisomerase enzymes. DNA gyrase (topoisomerase II), the target of fluoroquinolone action in Gram-negative bacteria, is involved in supercoiling and uncoiling the double helix DNA of prokaryotes. Topoisomerase IV, the target in Gram-positive bacteria, is involved in breaking the duplicated DNA of replicated prokaryotic DNA, preventing formation of daughter cells. By this mechanism, quinolones are rapidly bactericidal. ${ }^{26,27}$

Fourth-generation fluoroquinolones include gatifloxacin and moxifloxacin. They contain a substitution of a methoxy group at position 8 of the quinolone ring, which allows for simultaneous inhibition of both DNA gyrase and topoisomerase IV in Gram-positive bacteria. ${ }^{28,29}$ This structural modification was made specifically to increase potency against Gram-positive bacteria further while maintaining the broad spectrum of Gram-negative activity observed with the older fluoroquinolones. ${ }^{30}$ In vitro susceptibility testing demonstrates this increased sensitivity to the fourthgeneration fluoroquinolones from $S$. aureus, coagulasenegative Staphylococci, and $S$. viridans isolates resistant to second- and third-generation fluoroquinolones. ${ }^{31}$

Functional and structural characteristics of the fourthgeneration fluoroquinolones may reduce the chance of microbial resistance. In addition to providing broad-spectrum activity, dual targeting of topoisomerases reduces the risk of resistance because concomitant mutations in both genes are less likely to occur than a single mutation required to cause resistance to the older fluoroquinolones. ${ }^{32-36}$ The 8-methoxy fluoroquinolone structure reduces susceptibility to efflux from the bacterial cell, further decreasing the risk of resistance. ${ }^{37}$ Two other mechanisms of bacterial resistance to fluoroquinolones include a change in permeability of the organism, and one that confers quinolone resistance in $S$. aureus. ${ }^{38}$

\section{Gatifloxacin}

Gatifloxacin is a fluoroquinolone co-developed by Kyorin and Bristol-Myers Squibb that has a 3-methylpiperazine group at position 7 of the quinolone ring and a methoxy group at position 8. Gatifloxacin was approved in 1999 in the US as Tequin $^{\circledR}$ (gatifloxacin, Bristol-Myers Squibb, New York, NY) for once-daily dosing therapy in acute bacterial exacerbation of chronic bronchitis, acute sinusitis, community-acquired pneumonia, pyelonephritis, gonorrhea, and complicated and uncomplicated cystitis. ${ }^{39}$ Systemic administration of gatifloxacin, however, was strongly associated with hospitalization for hypoglycemia and hyperglycemia. With the exception of a slight increase in the risk of hypoglycemia with levofloxacin, this association was not shared by other fluoroquinolones. ${ }^{40}$ Several months following this report in 2006, Tequin was removed from the North American market.

\section{Ophthalmic use}

\section{Development of ophthalmic gatifloxacin}

A topical formulation of gatifloxacin called Zymar ${ }^{\circledR}$ (gatifloxacin $0.3 \%$ [3 mg/mL], Allergan Labs, Irvine, CA) was introduced in 2003 for the treatment of acute bacterial conjunctivitis in May 2010, the Food and Drug Administration approved a more concentrated formulation called Zymaxid $^{\mathrm{TM}}$ (gatifloxacin 0.5\% [5 mg/mL], Allergan Labs, Irvine, CA). Both are indicated for the treatment of bacterial conjunctivitis caused by susceptible organisms, and are also used in an offlabel manner in the treatment of bacterial keratitis and for prophylaxis of endophthalmitis following ocular surgery. ${ }^{29}$ The most frequently reported adverse events related to both products were conjunctival irritation, increased lacrimation, keratitis, papillary conjunctivitis, and altered taste. ${ }^{41,42}$ There have been no reports of dysglycemia associated with topical gatifloxacin use.

\section{Current studies}

Nonapproved indications/in vitro studies

Oliveira et al compared in vitro minimum inhibitory concentrations (MICs) and susceptibility profiles for ofloxacin, 
ciprofloxacin, gatifloxacin, and moxifloxacin in Gram-positive and Gram-negative isolates from cases of keratitis, conjunctivitis, and endophthalmitis. The MICs for gatifloxacin and moxifloxacin were significantly lower than for ciprofloxacin and ofloxacin for all Gram-positive organisms tested (S. aureus, methicillinresistant coagulase-negative Staphylococcus, methicillinsusceptible coagulase-negative Staphylococcus, S. pneumoniae, S. viridans). For the Gram-negative organisms tested (Haemophilus species, P. aeruginosa, Serratia species, Moraxella species) ciprofloxacin and gatifloxacin had significantly lower MICs than moxifloxacin and ofloxacin. ${ }^{43}$

Kowalski et al compared susceptibilities to various fluoroquinolones of 20 isolates each of fluoroquinolonesusceptible $S$. aureus, fluoroquinolone-resistant $S$. aureus, S. pneumoniae, and Haemophilus species. Moxifloxacin and gatifloxacin were the most potent against Gram-positive bacteria, and gatifloxacin and ciprofloxacin to be the most potent fluoroquinolones for Haemophilus species. ${ }^{44}$

Kowalski et al similarly reported susceptibility results from 177 keratitis isolates collected from 1993 to 2001. $S$. pneumoniae and $S$. viridans groups were more susceptible to moxifloxacin and gatifloxacin compared with ofloxacin and ciprofloxacin. The MICs of the fourth-generation fluoroquinolones were significantly lower in all groups compared with levofloxacin and ciprofloxacin for Gram-positive bacteria. Moxifloxacin did tend to have lower MICs compared with gatifloxacin against Gram-positive bacteria. However, the MICs of gatifloxacin were significantly lower than moxifloxacin for most Gram-negative bacteria tested. ${ }^{45}$

Mather et al examined susceptibility results from 93 bacterial endophthalmitis isolates. Coagulase-negative Staphylococci were more susceptible $(P=0.02)$ to gatifloxacin and moxifloxacin than levofloxacin, ciprofloxacin, and ofloxacin. $S$. viridans was more susceptible $(P=0.02)$ to moxifloxacin, gatifloxacin, and levofloxacin than ciprofloxacin and ofloxacin. These authors also reported that moxifloxacin and gatifloxacin were equally potent for second-generation fluoroquinoloneresistant coagulase-negative Staphylococcus and Bacillus species. ${ }^{31}$ Comparative in vitro susceptibilities and MICs of ciprofloxacin, gatifloxacin, and moxifloxacin against selected ocular pathogens have also been reviewed. ${ }^{46}$

Benzalkonium chloride (BAK) is a preservative found in many ophthalmic formulations, including gatifloxacin (Zymar and Zymaxid). BAK is a quaternary ammonium compound that has been consistently demonstrated to have synergistic antibacterial activity in vitro. ${ }^{47-51}$ It has been reported that the MICs of various organisms for gatifloxacin with BAK, organism eradication time, and fluoroquinolone-resistant strains are significantly reduced when compared with unpreserved gatifloxacin, moxifloxacin, or other classes of fluoroquinolones. Romanowski et al published the results of a New Zealand white rabbit model of gatifloxacin-resistant S. aureus-induced keratitis. Four hours after bacterial inoculation, the rabbit eyes were treated with gatifloxacin $0.3 \%$ plus $0.005 \%$ BAK, gatifloxacin $0.3 \%$ with BAK, BAK alone, or saline every 15 minutes for four hours. One hour after the end of treatment, the gatifloxacin + BAK group was noted to have significantly lower colony counts per cornea when compared with the group treated with gatifloxacin alone $(P<0.05)$. However, the mean colony-forming-unit $(\mathrm{CFU})$ count with BAK alone was not significantly different from the control group, suggesting there might have been some synergistic effect of gatifloxacin + BAK on the fluoroquinolone-resistant strain of MRSA..$^{52,53}$

There has been some discussion regarding the speed of kill of certain classes of antibiotics especially as it relates to increasing efficacy and therefore decreasing days off school or work in patients with bacterial conjunctivitis. In addition, because of the off-label use of antibiotic prophylaxis prior to ocular surgery for the prevention of endophthalmitis, rapid speed of killing may be important in the immediate preoperative period. Hyon et al assessed the time-kill activity of Zymar (gatifloxacin $0.3 \%$ ) and Vigamox ${ }^{\circledR}$ (moxifloxacin $0.5 \%$, Alcon Laboratories Inc, Fort Worth, TX) against isolates of $S$. aureus and coagulase-negative Staphylococcus at 15 minutes, 30 minutes, and 60 minutes. The mean $\log$ CFU of Staphylococci recovered after incubation with gatifloxacin was significantly lower than after incubation with moxifloxacin at 15 minutes (mean $0.47 \pm 1.12 \mathrm{log}$ $\mathrm{CFU} / \mathrm{mL}$ versus $4.55 \pm 0.60 \log \mathrm{CFU} / \mathrm{mL}$ ), 30 minutes (mean $0.07 \pm 0.31 \log \mathrm{CFU} / \mathrm{mL}$ versus $3.82 \pm 1.07 \log$ $\mathrm{CFU} / \mathrm{mL}$ ), and 60 minutes (mean $0.00 \pm 0.00 \log \mathrm{CFU} / \mathrm{mL}$ versus $2.75 \pm 1.29 \log \mathrm{CFU} / \mathrm{mL}, P<0.005)$. Similar results were seen against the coagulase-negative Staphylococci isolates. ${ }^{54}$ Callegan et al compared kill rates for Zymar and Vigamox against various isolates. Gatifloxacin was able to eradicate $H$. influenzae and $S$. pneumoniae completely in five minutes; MRSA, methicillin-resistant S. epidermidis, and fluoroquinolone-resistant $S$. epidermidis in 15 minutes; and S. aureus in 60 minutes. Moxifloxacin was able to eradicate $S$. pneumoniae by 60 minutes, but was unable to eradicate the other isolates completely by 60 minutes. ${ }^{55}$

In vitro susceptibility and resistance, in accordance with Clinical and Laboratory Standards Institute (CLSI) standards, are based on safe achievable concentrations in the serum after systemic administration. However, localized concentrations 
of fluoroquinolones have been shown to be higher than those achieved in the serum after systemic administration, even after only a few doses. ${ }^{56}$ In a rabbit keratitis model, corneas were inoculated with $S$. aureus isolates shown to be resistant to gatifloxacin (MIC $64 \mu \mathrm{g} / \mathrm{mL}$ ), levofloxacin (MIC $32 \mu \mathrm{g} / \mathrm{mL}$ ), and ciprofloxacin (MIC $256 \mu \mathrm{g} / \mathrm{mL}$ ) based on CLSI standards. Despite in vitro resistance, aggressive treatment with Zymar, which is consistent with the typical and recommended dosing schedule for off-label keratitis treatment, significantly reduced the amount of viable $S$. aureus recovered from the corneas and significantly reduced the signs of infection compared with second- and third-generation fluoroquinolones, and was as effective as fortified cefazolin and vancomycin. ${ }^{57}$

Several studies have examined penetration of gatifloxacin into ocular tissues and aqueous humor. ${ }^{58-62}$ In general, gatifloxacin is able to permeate tissue and get into the eye to some degree. However, it does not penetrate ocular tissues or achieve as high a concentration in aqueous as moxifloxacin. In a rabbit model, mean moxifloxacin concentration in the conjunctiva was significantly higher than either levofloxacin $(P=0.0191)$ or gatifloxacin $(P=0.0236) .{ }^{63}$ This trend is repeatable in human studies. Aihara et al compared levofloxacin, gatifloxacin, and moxifloxacin levels in diseased pterygium tissue collected at 10, 30, and 45 minutes after a single dose. They found that the concentration of moxifloxacin was higher than for the other fluoroquinolones at all sample times, with a maximum concentration of $116.7 \pm 28.9 \mu \mathrm{g} / \mathrm{g}$ at 10 minutes after instillation. At 30 minutes, the mean concentrations of levofloxacin, gatifloxacin, and moxifloxacin were $11.3 \pm 2.3 \mu \mathrm{g} / \mathrm{g}, 11.8 \pm 3.9 \mu \mathrm{g} / \mathrm{g}$, and $19.0 \pm 6.3 \mu \mathrm{g} / \mathrm{g}$, respectively. ${ }^{64}$ Wagner et al yielded comparable levofloxacin and gatifloxacin concentrations ( $2.34 \mu \mathrm{g} / \mathrm{g}$ and $2.54 \mu \mathrm{g} / \mathrm{g}$, respectively) in healthy conjunctiva collected at 20 minutes after a single dose. ${ }^{65}$ Tordkildsen et al found peak mean concentration in conjunctiva from one drop of besifloxacin, gatifloxacin, and moxifloxacin to be $2.30 \pm 1.42 \mu \mathrm{g} / \mathrm{g}, 4.03 \pm 3.84 \mu \mathrm{g} / \mathrm{g}$, and $10.7 \pm 5.89 \mu \mathrm{g} / \mathrm{g}$, respectively. ${ }^{66}$ However, in the treatment of bacterial conjunctivitis, where the infection is external to ocular tissue, a high degree of penetration may not be necessary.

\section{In bacterial conjunctivitis}

In Phase III trials of Zymar where patients were dosed for five days, gatifloxacin was found to be superior to its vehicle on days 5-7 in patients with conjunctivitis and positive conjunctival cultures. The clinical cure rate was reported to be $77 \%(40 / 52)$ for the gatifloxacin-treated group versus 58\% (28/48) for the placebo-treated group. Also reported was a statistically superior eradication for causative pathogens of $92 \%(48 / 52)$ for gatifloxacin versus $72 \%$ (34/48) for placebo. ${ }^{41}$

A multicenter, investigator-masked, randomized clinical trial comparing the efficacy of gatifloxacin ophthalmic solution $0.3 \%$ administered for five days either twice daily or four times daily in patients with acute bacterial conjunctivitis suggested that twice daily versus four times daily dosing had similar clinical cure rates within its intent-to-treat group and within its per-protocol group. In the twice daily group $86.5 \%$ $(45 / 52)$ and in the four times daily group $71.2 \%(37 / 52)$ achieved clinical cure on day $5(P=0.096)$. However, this study was limited by its small population of patients. ${ }^{67}$

In Phase III trials of Zymaxid, patients with conjunctivitis and positive conjunctival cultures were dosed for five days. Clinical outcomes for the trials demonstrated clinical success (resolution of conjunctival hyperemia and discharge) of $58 \%(193 / 333)$ for the gatifloxacin-treated groups versus 45\% (148/325) for the vehicle-treated groups. Microbiological outcomes for the same clinical trials demonstrated a statistically superior eradication rate for causative pathogens of $90 \%$ (301/333) for gatifloxacin versus $70 \%(228 / 325)$ for the vehicle. ${ }^{42}$

The Charles T Campbell Eye Microbiology Laboratory at the University of Pittsburg continuously monitors antibiotic susceptibilities of organisms isolated from various ocular infections (http://eyemicrobiology.upmc.com/ AntibioticSusceptibilities/Conjunctivitis.htm). They report that $100 \%$ of S. pneumoniae, Haemophilus species, Moraxella species, and Acinetobacter species cultured from patients with conjunctivitis and blepharitis were susceptible to gatifloxacin and moxifloxacin. Coagulase-negative Staphylococcus isolates were $58 \%$ susceptible to both. $S$. aureus isolates were $81 \%$ and $84 \%$ susceptible to gatifloxacin and moxifloxacin, respectively. Gram-negative organisms were extremely susceptible. Of all the Gram-negative cultures, a single isolate of $P$. aeruginosa was resistant to moxifloxacin, and a single isolate of Stenotrophomonas maltophilia was resistant to both gatifloxacin and moxifloxacin. These data are specific to this region of the US, and are based on current CLSI breakpoint data for systemic dosing of susceptible, intermediate, and resistant MICs. It is assumed that with the higher concentrations of commercially available topical gatifloxacin and the potential to dose at a higher frequency than systemic gatifloxacin, the breakpoint MIC would be higher, and therefore, less bacteria would be intermediately or resistant to gatifloxacin. However, this hypothesis cannot be proven with current testing because "ocular" breakpoints do not exist. One thing is for certain, these in vitro data are not a direct indication of clinical efficacy. 


\section{Conclusion}

Bacterial conjunctivitis is a mostly self-limiting eye disease with rare permanent sequelae, even when left untreated. The role of antibiotic treatment is well described and allows for a shorter time to clinical and microbiological cure. When therapy is warranted, cost, toxicity, and dosing frequency may influence the choice of antibiotic more than its potency.

Gatifloxacin ophthalmic solution is a fourth-generation fluoroquinolone with BAK preservative and broad-spectrum activity. It has had a relatively low resistance profile, but there are data suggesting that resistant strains based on systemic breakpoints are quickly rising. How these increased in vitro MIC findings affect clinical success or failure is not known, but it is an ominous trend. Because of this concern of selecting for resistant strains, and because many studies show equivalent results among various antibiotics in the treatment of bacterial conjunctivitis, it would be prudent to consider speed of kill, cost, toxicity, dosing frequency, antibacterial spectrum, and likely pathogen when deciding on which anti-infective treatment to initiate. Among the myriad of options, fluoroquinolones, including gatifloxacin, can be considered an excellent option.

\section{Disclosure}

FSM receives grant and research support from Alcon, Allergan, Inspire, and Ox-danthia, and is a consultant to Alcon, Allergan, Inspire, Ista, Ox-danthia, Foresight, and Ocular Therapeutix. LJC has no disclosures to make.

\section{References}

1. Chiang YP, Wang F, Javitt JC. Office visits to ophthalmologists and other physicians for eye care among the US population, 1990. Public Health Rep. 1995;110(2):147-153.

2. Soukiasian SH, Baum J. Bacterial conjunctivitis. In: Krachmer JH, Mannis MJ, Holland EJ, editors. Cornea. 3rd ed. Philadelphia, PA: Elsevier Mosby; 2010.

3. Perkins RE, Kundsin RB, Pratt MV, Abrahamsen I, Leibowitz HM. Bacteriology of normal and infected conjunctiva. J Clin Microbiol. 1975 1(2):147-149.

4. Brook I, Pettit TH, Martin WJ, Finegold SM. Anaerobic and aerobic bacteriology of acute conjunctivitis. Ann Ophthalmol. 1979;11(3):389-393.

5. Everett SL, Kowalski RP, Karenchak LM, Landsittel D, Day R, Gordon YJ. An in vitro comparison of the susceptibilities of bacterial isolates from patients with conjunctivitis and blepharitis to newer and established topical antibiotics. Cornea. 1995;14(4):382-387.

6. Cavuoto K, Zutshi D, Karp CL, Miller D, Feuer W. Update on bacterial conjunctivitis in South Florida. Ophthalmology. 2008;115(1):51-56.

7. Gigliotti F, Williams WT, Hayden FG, et al. Etiology of acute conjunctivitis in children. J Pediatr. 1981;98(4):531-536.

8. Borer A, Livshiz-Riven I, Golan A, et al. Hospital-acquired conjunctivitis in a neonatal intensive care unit: Bacterial etiology and susceptibility patterns. Am J Infect Control. 2010;38(8):650-652.

9. Adebayo A, Parikh JG, McCormick SA, et al. Shifting trends in in vitro susceptibilities for common bacterial conjunctival isolates in the last decade at the New York Eye and Ear Infirmary. Arch Clin Exp Ophthalmol. 2011;249(1):111-119.
10. American Academy of Ophthalmology. Preferred practice patterns: Conjunctivitis, 2008. Available from: http://one.aao.org/CE/Practice Guidelines/PPP.aspx. Accessed December 28, 2010.

11. Patel PB, Diaz MC, Bennett JE, Attia MW. Clinical features of bacterial conjunctivitis in children. Acad Emerg Med. 2007;14(1):1-5.

12. Buznach N, Dagan R, Greenberg D. Clinical and bacterial characteristics of acute bacterial conjunctivitis in children in the antibiotic resistance era. Pediatr Infect Dis J. 2005;24(9):823-828.

13. Smolin G, Okumoto M. Staphylococcal blepharitis. Arch Ophthalmol. 1977;95(5):812-816.

14. Van Bijsterveld OP. The incidence of Moraxella on mucous membranes and the skin. Am J Ophthalmol. 1972;74(1):72-76.

15. Aung T, Chan TK. Nosocomial Klebsiella pneumoniae conjunctivitis resulting in infectious keratitis and bilateral corneal perforation. Cornea. 1998;17(5):558-561.

16. King S, Devi SP, Mindorff C, Patrick ML, Gold R, Ford-Jones EL. Nosocomial Pseudomonas aeruginosa conjunctivitis in a pediatric hospital. Infect Control Hosp Epidemiol. 1988;9(2):77-80.

17. Sheikh A, Hurwitz B. Topical antibiotics for acute bacterial conjunctivitis: Cochrane systematic review and meta-analysis update. Br J Gen Pract. 2005;55(521):962-964.

18. Rose PW, Ziebland S, Harnden A, Mayon-White R, Mant D. Oxford Childhood Infection Study Group (OXCIS). Why do general practitioners prescribe antibiotics for acute infective conjunctivitis in children? Qualitative interview with GPs and a questionnaire survey of parents and teacher. Fam Pract. 2006;23(2):226-232.

19. Baum J, Barza M. The evolution of antibiotic therapy for bacterial conjunctivitis and keratitis: 1970-2000. Cornea. 2000;19(5): 659-672.

20. Rose P. Management strategies for acute infective conjunctivitis in primary care: A systematic review. Expert Opin Pharmacother. 2007; 8(12):1903-1921.

21. Gibson JR. Trimethoprim-polymyxin B ophthalmic solution in the treatment of presumptive bacterial conjunctivitis - a multicentre trial of its efficacy versus neomycin-polymyxin B-gramicidin and chloramphenicol ophthalmic solutions. J Antimicrob Chemother. 1983;11(3): 217-221

22. Everitt H, Little P. How do GPs diagnose and manage acute infective conjunctivitis? A GP survey. Fam Pract. 2002;19(6):658-660.

23. Everitt HA, Little PS, Smith PW. A randomised controlled trial of management strategies for acute infective conjunctivitis in general practice. BMJ. 2006;333(7563):321.

24. Kowalski RP, Karenchak LM, Romanowski MS. Infectious disease: Changing antibiotic susceptibility. Ophthalmol Clin North Am. 2003 16(1):1-9.

25. Asbell PA, Colby KA, Deng S, et al. Ocular TRUST: Nationwide antimicrobial susceptibility patterns in ocular isolates. Am J Ophthalmol. 2008;145(6):951-958.

26. Mah FS. Fourth-generation fluoroquinolones: New topical agents in the war on ocular bacterial infections. Curr Opin Ophthalmol. 2004;15(4):316-320.

27. Hooper DC, Wolfson JS. Fluoroquinolone antimicrobial agents. N Engl J Med. 1991;324(6):384-394.

28. Fish DN, North DS. Gatifloxacin, an advanced 8-methoxy fluoroquinolone. Pharmacotherapy. 2001;21(1):35-59.

29. Olson R. Zymar ${ }^{\circledR}$ as an ocular therapeutic agent. Int Ophthalmol Clin. 2006;46(4):73-84

30. Blondeau JM, Laskowski R, Bjarnason J, Stewart C. Comparative in vitro activity of gatifloxacin, grepafloxacin, levofloxacin, moxifloxacin and trovafloxacin against 4151 Gram-negative and Gram-positive organisms. Int J Antimicrob Agents. 2000;14(1):45-50.

31. Mather R, Karenchak LM, Romanowski EG, Kowalski RP. Fourth generation fluoroquinolones: New weapons in the arsenal of ophthalmic antibiotics. Am J Ophthalmol. 2002;133(4):463-466.

32. Scoper SV. Review of third-and fourth-generation fluoroquinolones in ophthalmology: In-vitro and in-vivo efficacy. Adv Ther. 2008;25(10): 979-994. 
33. Sanders CC. Review of preclinical studies with ofloxacin. Clin Infect Dis. 1992;14(2):526-538.

34. Wiseman LR, Balfour JA. Ciprofloxacin. A review of its pharmacological profile and therapeutic use in the elderly. Drugs Aging. 1994;4(2): 145-173.

35. Khodursky AB, Zechiedrich EL, Cozzarelli NR. Topoisomerase IV is a target of quinolones in Escherichia coli. Proc Natl Acad Sci US A. 1995;92(25):11801-11805.

36. Breines DM, Ouabdesselam S, Ng EY, et al. Quinolone resistance locus nfxD of Escherichia coli is a mutant allele of the parE gene encoding a subunit of topoisomerase IV. Antimicrob Agents Chemother. 1997;41(1):175-179.

37. Pestova E, Millichap JJ, Noskin GA, Peterson LR. Intracellular targets of moxifloxacin: A comparison with other fluoroquinolones. J Antimicrob Chemother. 2000;45(5):583-590.

38. Wolfson JS, Hooper DC. Bacterial resistance to quinolones: Mechanisms and clinical importance. Rev Infect Dis. 1989;11 Suppl 5:S960-S968.

39. Brown WM. Gatifloxacin Kyorin Pharmaceutical Co. Curr Opin Investig Drugs. 2000;1(1):35-44.

40. Park-Wyllie LY, Juurlink DN, Kopp A, et al. Outpatient gatifloxacin therapy and dysglycemia in older adults. N Engl J Med. 2006;354(13): 1352-1361.

41. Zymar ${ }^{\circledR}$ [Package insert]. Irvine, CA: Allergan Inc; 2003.

42. Zymaxid ${ }^{\mathrm{TM}}$ [Package insert]. Irvine, CA: Allergan Inc; 2010.

43. Oliveira AD, D'Azevedo PA, Francisco W. In vitro activity of fluoroquinolones against ocular bacterial isolates in Sao Paulo, Brazil. Cornea. 2007;26(2):194-198.

44. Kowalski RP, Yates KA, Romanowski EG, Karenchak LM, Mah FS, Gordon YJ. An ophthalmologist's guide to understanding antibiotic susceptibility and minimum inhibitory concentration data. Ophthalmology. 2005;112:1987-1991.

45. Kowalski RP, Dhaliwal DK, Karenchak LM, et al. Gatifloxacin and moxifloxacin: An in vitro susceptibility comparison to levofloxacin, ciprofloxacin, and ofloxacin using bacterial keratitis isolates. $\mathrm{Am} \mathrm{J}$ Ophthalmol. 2003;136(3):500-505.

46. Miller D. Review of moxifloxacin hydrochloride ophthalmic solution in the treatment of bacterial eye infections. Clin Ophthalmol. 2008;2(1): 77-91.

47. Blondeau JM, Borsos S, Hesje CK. Antimicrobial efficacy of gatifloxacin and moxifloxacin with and without benzalkonium chloride compared with ciprofloxacin and levofloxacin against methicillin-resistant Staphylococcus aureus. J Chemother. 2007;19(2):146-151.

48. Callegan MC, Novosad BD, Ramadan RT, Wiskur B, Moyer AL. Rate of bacterial eradication by ophthalmic solutions of fourth-generation fluoroquinolones. Adv Ther. 2009;26(4):447-454

49. Hesje CK, Borsos SD, Blondeau JM. Benzalkonium chloride enhances antibacterial activity of gatifloxacin and reduces its propensity to select for fluoroquinolone-resistant strains. J Ocul Pharmacol Ther. 2009;25(4):329-334.

50. Blondeau JM, Hedlin P, Borsos SD. The antimicrobial activity of gatifloxacin (GAT) with or without benzalkonium chloride (BAK) against ocular bacterial pathogens. Invest Ophthalmol Vis Sci. 2005;46:Abstr 4880.

51. E Borsos SD, Blondeau JM, Hesje CK. Comparative in vitro potency of levofloxacin (Lfx) and gatifloxacin (Gfx) plus benzalkonium chloride (BAK) against gram-positive (GP) pathogens including methicillinresistant Staphylococcus aureus (MRSA). Invest Ophthalmol Vis Sci. 2008;49:Abstr 1980

Clinical Ophthalmology

\section{Publish your work in this journal}

Clinical Ophthalmology is an international, peer-reviewed journal covering all subspecialties within ophthalmology. Key topics include: Optometry; Visual science; Pharmacology and drug therapy in eye diseases; Basic Sciences; Primary and Secondary eye care; Patient Safety and Quality of Care Improvements. This journal is indexed on Submit your manuscript here: http://www.dovepress.com/clinical-ophthalmology-journal
52. McDonald M, Blondeau JM. Emerging antibiotic resistance in ocular infections and the role of fluoroquinolones. $J$ Cataract Refract Surg. 2010;36(9):1588-1598.

53. Romanowski EG, Mah FS, Kowalski RP, Yates KA, Gordon YJ. Benzalkonium chloride enhances the antibacterial efficacy of gatifloxacin in an experimental rabbit model of intrastromal keratitis. $J$ Ocul Pharmacol Ther. 2008;24(4):380-384.

54. Hyon JY, Eser I, O'Brien TP. Kill rates of preserved and preservativefree topical 8-methoxyfluoroquinolones against various strains of Staphylococcus. J Cataract Refract Surg. 2009;35(9):1609-1613.

55. Callegan MC, Novosad BD, Ramadan RT, Wiskur B, Moyer AL. Rate of bacterial eradication by ophthalmic solutions of fourth-generation fluoroquinolones. Adv Ther. 2009;26(4):447-454.

56. Kowalski RP, Karenchak LM, Gordon YJ. Comparison of ciprofloxacin and ofloxacin using human corneal susceptibility levels. Cornea. 1998;17(3):282-287.

57. Romanowski EG, Mah FS, Yates KA, Kowalski RP, Gordon YJ. The successful treatment of gatifloxacin-resistant Staphylococcus aureus keratitis with Zymar ${ }^{\circledR}$ (gatifloxacin 0.3\%) in a NZW rabbit model. Am J Ophthalmol. 2005;139(5):867-877.

58. Kim DH, Stark WJ, O'Brien TP, Dick JD. Aqueous penetration and biological activity of moxifloxacin $0.5 \%$ ophthalmic solution and gatifloxacin $0.3 \%$ solution in cataract surgery patients. Ophthalmology. 2005;112(11):1992-1996

59. Solomon R, Donnenfeld ED, Perry HD, et al. Penetration of topically applied gatifloxacin $0.3 \%$, moxifloxacin $0.5 \%$, and ciprofloxacin $0.3 \%$ into the aqueous humor. Ophthalmology. 2005;112(3):466-469.

60. McCulley JP, Caudle D, Aronowicz JD, Shine WE. Fourth-generation fluoroquinolone penetration into the aqueous humor in humans. Ophthalmology. 2006;113(6):955-959.

61. Katz HR, Masket S, Lane SS, et al. Absorption of topical moxifloxacin ophthalmic solution into human aqueous humor. Cornea. 2005;24(8): 955-958.

62. Ong-Tone L. Aqueous humor penetration of gatifloxacin and moxifloxacin eyedrops given by different methods before cataract surgery. $J$ Cataract Refract Surg. 2007;33(1):59-62.

63. Sugioka K, Fukuda M, Komoto S, Itahashi M, Yamada M, Shimomura Y. Intraocular penetration of sequentially instilled topical moxifloxacin, gatifloxacin, and levofloxacin. Clin Ophthalmol. 2009;3:553-557.

64. Aihara M, Miyanaga M, Minami K, et al. A comparison of fluoroquinolone penetration into human conjunctival tissue. J Ocul Pharmacol Ther. 2008;24(6):587-591.

65. Wagner RS, Abelson MB, Shapiro A, Torkildsen G. Evaluation of moxifloxacin, ciprofloxacin, gatifloxacin, ofloxacin, and levofloxacin concentrations in human conjunctival tissue. Arch Ophthalmol. 2005; 123(9):1282-1283.

66. Torkildsen G, Proksch JW, Shapiro A, Lynch SK, Comstock TL. Concentrations of besifloxacin, gatifloxacin, and moxifloxacin in human conjunctiva after topical ocular administration. Clin Ophthalmol. 2010;4:331-341.

67. Yee RW, Tepedino M, Bernstein P, Jensen H, Schiffman R, Whitcup SM. A randomized, investigator-masked clinical trial comparing the efficacy and safety of gatifloxacin $0.3 \%$ administered BID versus QID for the treatment BID versus QID for the treatment of acute bacterial conjunctivitis of acute bacterial conjunctivitis. Curr Med Res Opin. 2005;21(3):425-431.

\section{Dovepress}

PubMed Central and CAS, and is the official journal of The Society of Clinical Ophthalmology (SCO). The manuscript management system is completely online and includes a very quick and fair peer-review system, which is all easy to use. Visit http://www.dovepress.com/ testimonials.php to read real quotes from published authors. 